\title{
3D Airway changes using cone beam computed tomography in patients following mandibular advancement surgery with and without constriction
}

\author{
Silja Furche $^{1}$ | Sean P. Edwards ${ }^{2}$ | Sharon Aronovich ${ }^{2}$ | Gregory Hummon ${ }^{3}$ | \\ Kanchi B. Shah ${ }^{4}$ | R. Scott Conley ${ }^{5}$
}

${ }^{1}$ Private Practice, Munich, Germany

${ }^{2}$ Department of Oral and Maxillofacial Surgery, University of Michigan, Ann Arbor, Michigan

${ }^{3}$ Department of Orthodontics and Pediatric Dentistry, University of Michigan, Ann Arbor, Michigan

${ }^{4}$ Bronx Care Hospital, Bronx, New York

${ }^{5}$ Department of Orthodontics, University at Buffalo, Buffalo, New York

\section{${ }^{*}$ Correspondence}

R. Scott Conley, University at Buffalo School of Dental Medicine, Buffalo, NY.

Email: rsconley@buffalo.edu

\begin{abstract}
Structured Abstract
Objectives: The aim of this study was to compare three-dimensional airway changes resulting from mandibular advancement surgery and mandibular advancement surgery with constriction.

Setting and Sample Population: The University of Michigan School of Dentistry and Medical Center. A total of 42 patients undergoing mandibular advancement with or without simultaneous constriction.

Materials and Methods: A retrospective airway evaluation of patients undergoing mandibular advancement with or without simultaneous mandibular constriction was performed. Cross-sectional evaluation at standardized locations, minimum cross section and volumetric analysis were performed using Dolphin Imaging TM Version 11.7. Results: Patients undergoing mandibular advancement with or without constriction experienced significant airway increases $(P<0.05)$. Patients who underwent mandibular advancement only gained nearly twice as much airway volume as mandibular advancement with simultaneous constriction $\left(8.69 \mathrm{~mm}^{3}\right.$ vs $4.3 \mathrm{~mm}^{3}$ ). The largest increase for both groups was observed in the minimum axial area in the oropharynx segment $\left(119.5 \mathrm{~mm}^{2}\right)$ and the axial area of the retroglossal region $\left(137.2 \mathrm{~mm}^{2}\right)$.

Conclusions: The findings demonstrate mandibular advancement with constriction results in airway enlargement following surgery.

KEYWORDS

airway remodelling, cone beam computed tomography, orthognathic surgery
\end{abstract}

\section{1 | INTRODUCTION}

Malocclusion caused by skeletal or dental factors is widespread with ethnicity being one factor in the type of malocclusion observed. Class II malocclusion is higher in Caucasians of Northern European descent, ${ }^{1,2}$ whereas the prevalence of Class III malocclusions is more commonly found in the Hispanic and Asian population which suggests a genetic component. ${ }^{3}$ According to the National Health and Nutrition Examination Survey (NHANES II), the prevalence of Class II malocclusion in adults in the United States approximates $13.4 \%{ }^{4}$
Class II can result from dentoalveolar abnormalities, skeletal malpositioning or both. In Class II dental malocclusions, the lower molar is distally positioned relative to the upper molar but the skeletal bases are appropriately positioned. For skeletal Class II malocclusion, the maxilla may be prognathic, the mandible retrognathic or a combination of both. ${ }^{5,6}$ The majority of Class II patients can be treated conventionally, however when the deformity is severe, surgical intervention may be indicated. ${ }^{7}$ Severe Class II malocclusion can, in some cases, also lead to medical comorbidities such as obstructive sleep apnoea ${ }^{8}$ which affects approximately $13 \%$ of males and $6 \%$ females in the general population. ${ }^{9}$ 
Orthognathic surgery for Class II may include single jaw or double jaw approaches. ${ }^{10,11}$ When planning surgical mandibular advancement, one must also consider the transverse dimension. ${ }^{12}$ Following advancement, a wider portion of the mandible articulates with a narrower portion of the maxilla. A common treatment is widening of the maxilla through orthopaedic rapid maxillary expansion (RME) in younger patients or surgically assisted RME in adults. ${ }^{13,14}$ An alternate approach is mandibular advancement with simultaneous constriction. $^{12,15}$

With the increased awareness of obstructive sleep apnoea, attention has focused on airway changes resulting from orthodontics and orthognathic surgery. Previous investigations have demonstrated that mandibular advancement is associated with an increase in the pharyngeal airway space (PAS). ${ }^{16,17}$ Many of these studies have employed lateral cephalograms. ${ }^{18-20}$ To overcome two-dimensional limitations, cone beam computed tomography (CBCT) has been used $^{20-22}$ to obtain a three-dimensional (3D) understanding of the resulting changes and quantification of the airway volume. While recent studies have demonstrated airway changes resulting from mandibular advancement alone, the possible impact of simultaneous mandibular advancement with constriction has not been evaluated. The specific aim of this retrospective study is to comprehensively evaluate the three-dimensional airway changes from CBCT scans in adult patients undergoing surgical mandibular advancement with and without simultaneous constriction.

\section{2 | MATERIALS AND METHODS}

Institutional review board exemption (HUM00108933) was granted for this retrospective study. Inclusion criteria included adult patients with preoperative (T1) and postoperative (T2) CBCT scans who underwent mandibular advancement surgery with or without constriction for the correction of Class II skeletal malocclusion. To control for variability in head position, only patients with consistent head posture $\left(<5^{\circ}\right)$ as assessed by measuring the craniocervical angle (N-S-Ba) were included. A total of 42 patients met the inclusion criteria, 17 underwent mandibular advancement surgery with constriction (11 female and 6 male) and 25 patients underwent advancement only ( 16 female and 9 male). Patients with syndromes, maxillary surgery or obstructive sleep apnoea (OSA) were excluded.

All scans were obtained with an EWOO Master 3DS ${ }^{\mathrm{TM}}$ CBCT scanner (EWOO Technology USA Inc. Houston, TX). The scan parameters were $90.0 \mathrm{kV}, 3.3 \mathrm{~mA}, 20 \times 19 \mathrm{~cm}$ field of view, $15 \mathrm{sec}-$ onds exposure time, normal quality mode, $0.2 \mathrm{~mm}$ slice thickness, isotropic voxel size of $0.40 \mathrm{~mm}$. All CBCT scans were de-identified, labelled saved in DICOM format.

Pre- and post-surgical cephalograms were extracted from the CBCT for every patient. The cephalograms were digitally traced (Figure 1) and analysed using the cephalometrics for orthognathic surgery (COGS) analysis (Dolphin Imaging ${ }^{\mathrm{TM}}$ Version 11.7).

\section{Cephalometric Landmarks:}

$\begin{array}{ll}\text { N: } & \text { Nasion } \\ \text { Ar: } & \text { Articulare } \\ \text { PTM: } & \text { Pterygomaxillary fissure } \\ \text { ANS: } & \text { Anterior nasal spine } \\ \text { PNS: } & \text { Posterior nasal spine } \\ \text { A: } & \text { A point } \\ \text { B: } & \text { B point } \\ \text { Pg: } & \text { Pogonion } \\ \text { Gn: } & \text { Gnathion } \\ \text { Me: } & \text { Menton } \\ \text { Go: } & \text { Gonion } \\ \text { U1: } & \text { Upper central incisor } \\ \text { U6: } & \text { Upper first molar } \\ \text { L1: } & \text { Lower central incisor } \\ \text { L6: } & \text { Lower first molar } \\ \text { OP: } & \text { Occlusal plane } \\ \text { HP: } & \text { Horizontal plane } \\ \text { MP: } & \text { Mandibular plane (constructed from } \\ & \text { Gonion to Menton) }\end{array}$

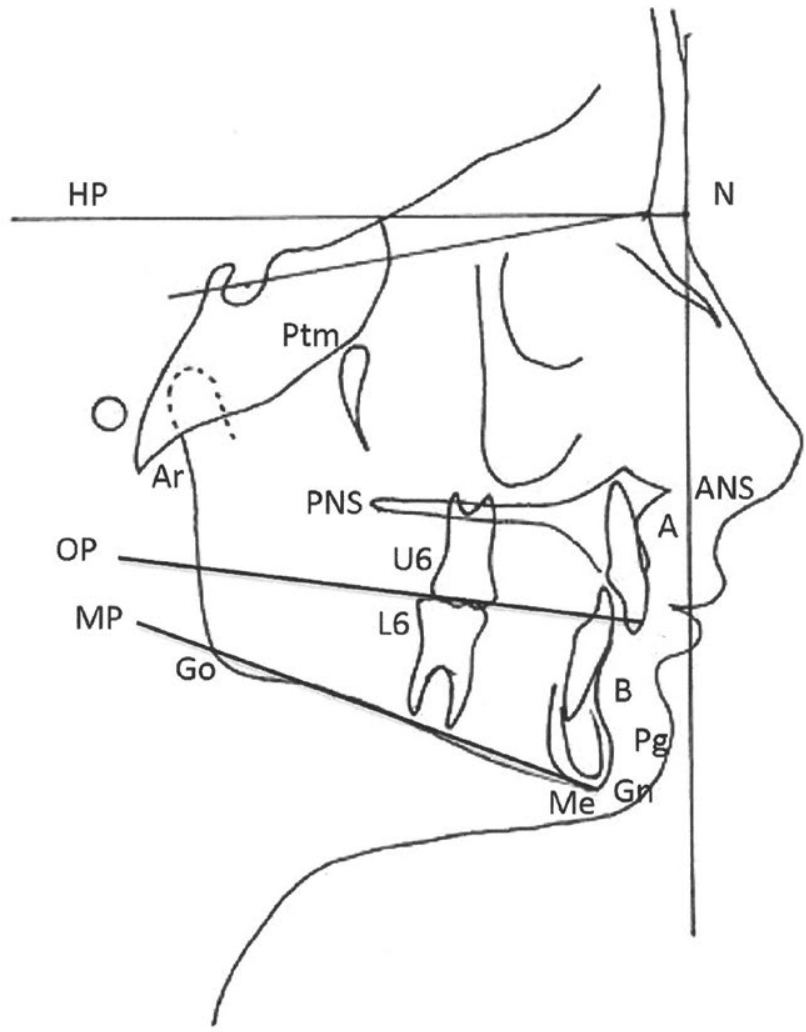

FIGURE 1 A representative lateral cephalometric tracing with landmarks from the cephalometrics for orthognathic surgery (COGS) analysis labelled 


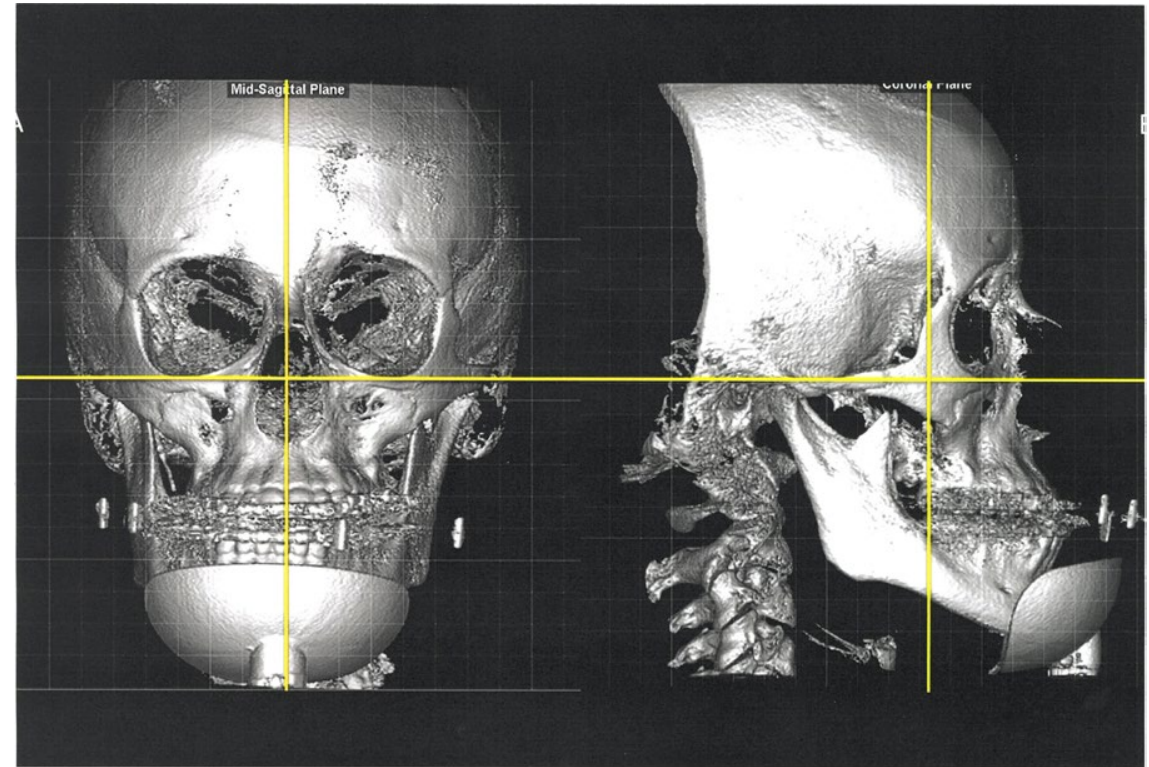

A: Orbits levelled with respect to horizontal reference plane

B: Zygomatic arch levelled with respect to horizontal reference plane.
FIGURE 2 A representative cone beam computed tomography (CBCT) scan used for orientation. A, In the frontal plane, the orbits are levelled with respect to horizontal reference grid. $\mathrm{B}$, In the sagittal plane, the zygomatic arch is levelled with respect to the horizontal reference grid
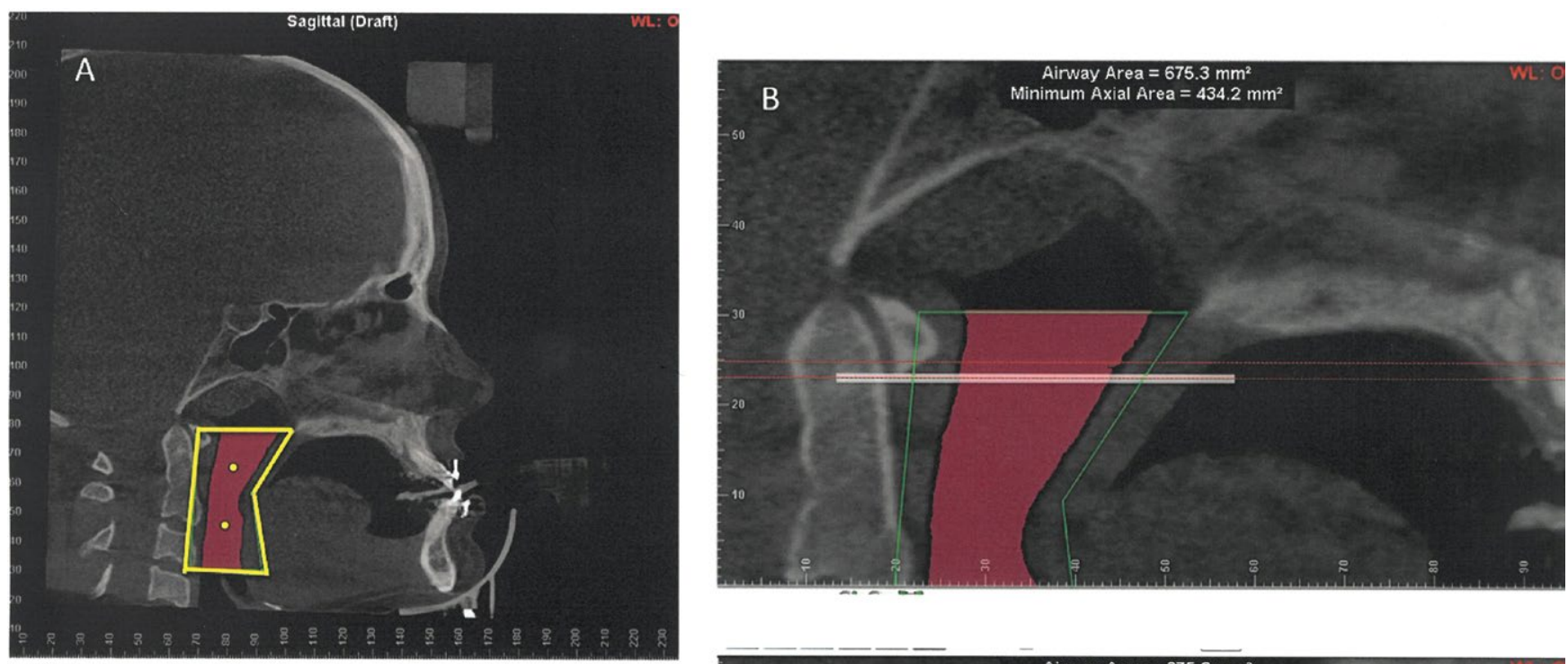

A: mid-sagittal slice from CBCT depicting the "seed" points (yellow dots), airway region of interest (yellow box) and airway volume (purple area). B: Retropalatal airway (tangent to anteriorinferior aspect of C1.) C: Retroglossal airway (tangent to anteriorinferior aspect of C2)

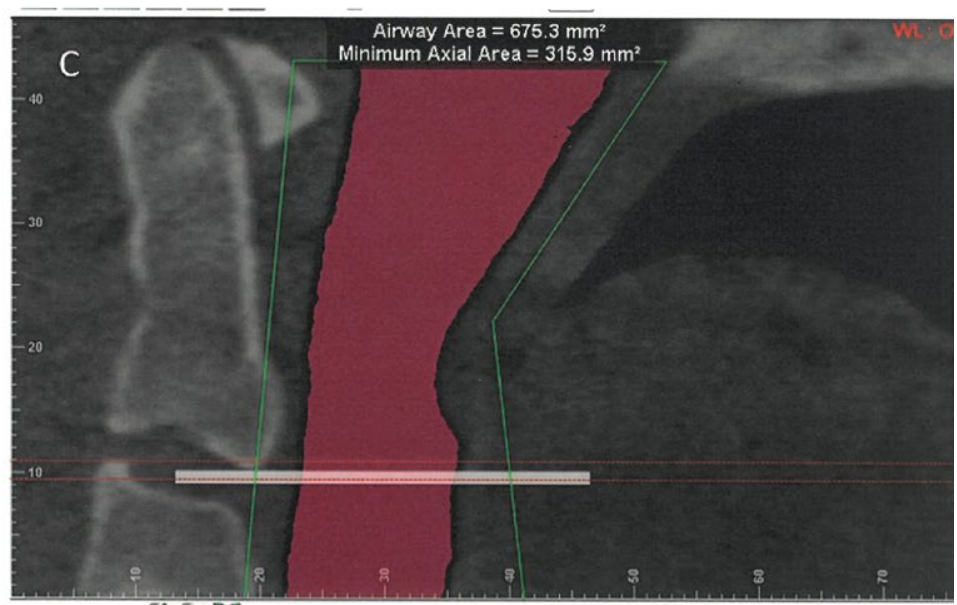

FIGURE 3 A representative cone beam computed tomography (CBCT) airway segmentation. A, Mid-sagittal slice from CBCT depicting the "seed" points (yellow dots), airway region of interest (yellow box) and airway volume (purple area). B, Retroplalatal airway (tangent to anterior-inferior aspect of C1). C, Retroglossal airway (tangent to anterior-inferior aspect of C2) 


\section{1 | Three-dimensional analysis}

Prior to analysis, all scans were reoriented for consistency (Figure 2). In the coronal plane (Figure 2A), the right and left inferior orbital borders were aligned horizontally. Sagittally (Figure 2B) the best fit of the zygomatic arch was aligned horizontally. Axially, the lateral walls of the orbits were placed tangent to each other.

The airway volume (Figure $3 \mathrm{~A}$ ) was bounded superiorly by the line extending from posterior nasal spine (PNS) to the posterior pharyngeal wall and inferiorly by a parallel line from the anterior-inferior border of C3 to the base of the tongue. The posterior limit was the posterior pharyngeal wall, and the anterior boundary was created by the soft palate and base of the tongue. Seed points were placed in the region of interest, and airway sensitivity was set to 73. Each scan was assessed to confirm the volume remained within anatomic airway boundaries.

Minimum axial airway was determined for entire airway as well as the retropalatal (Figure 3B: anterior-inferior border of $\mathrm{C} 1$ ) and retroglossal (Figure $3 \mathrm{C}$ anterior-inferior of $\mathrm{C} 2$ ) regions.

The amount of constriction was assessed using the millimetric distance between the right and left gonial angles, the mesial lingual cusps of the mandibular first molars and cusps of the mandibular canines pre- and post-operatively.

\section{2 | Statistical analysis}

ANOVA was performed to confirm similar start forms between presurgical groups. Paired $t$ tests performed for $2 \mathrm{~d}$ and $3 \mathrm{~d}$ comparison of preoperative to postoperative changes within groups. Welch's unpaired $t$ test was used to compare the changes pre- and post-surgically between the BSSO with constriction group and the BSSO only group. Statistical significance was set a $P<0.05$.

For intra- and inter-examiner reliability, a random number generator was used to select 10 scans from both groups. The measurements were repeated 2 months after the initial measurements. Both intra- and inter-examiner reliability tests exhibited high correlation ranging from 0.912 to 0.982 for all measures.

\section{3 | RESULTS}

\section{1 | Cephalometric results}

ANOVA revealed no significant differences between the mandibular advancement alone and the mandibular advancement with constriction groups presurgically (T1) (Table 1) Mean mandibular advancement (T2-T1) was $5.8 \mathrm{~mm}$ in the constriction group and $5.5 \mathrm{~mm}$ in

TAB LE 1 Comparison of Mandibular advancement without (-) and mandibular advancement with (+) constriction cephalomectric analysis

\begin{tabular}{|c|c|c|c|c|c|c|}
\hline \multirow[b]{2}{*}{ Measure } & \multicolumn{3}{|c|}{$\mathrm{T} 1$} & \multicolumn{3}{|c|}{ T2 } \\
\hline & BSSO (-) & BSSO (+) & $P$ & BSSO (-) & BSSO (+) & $P$ \\
\hline $\operatorname{Ar}-\mathrm{PTM}(/ / \mathrm{HP})(\mathrm{mm})$ & $33.4 \pm 3.7$ & $30.5 \pm 4.8$ & 0.0804 & $33.3 \pm 3.8$ & $30.7 \pm 3.7$ & 0.07 \\
\hline PTM-N (//HP) (mm) & $58.1 \pm 3.7$ & $58.4 \pm 4.5$ & 0.4370 & $58.0 \pm 3.7$ & $58.7 \pm 4.0$ & 0.62 \\
\hline N-A-Pg (//) & $11.4 \pm 9.6$ & $14.3 \pm 6.7$ & 0.2945 & $5.8 \pm 7.7$ & $6.0 \pm 6.2$ & 0.92 \\
\hline $\mathrm{N}-\mathrm{A}(/ / \mathrm{HP})(\mathrm{mm})$ & $-1.9 \pm 5.0$ & $-3.2 \pm 7.4$ & 0.5423 & $-1.8 \pm 5.0$ & $-4.9 \pm 4.9$ & 0.09 \\
\hline $\mathrm{N}-\mathrm{B}(/ / \mathrm{HP})(\mathrm{mm})$ & $-15.9 \pm 9.9$ & $-20.3 \pm 11.9$ & 0.2630 & $-10.3 \pm 8.2$ & $-14.6 \pm 9.6$ & 0.19 \\
\hline $\mathrm{N}-\mathrm{Pg}(/ / \mathrm{HP})(\mathrm{mm})$ & $-15.3 \pm 11.9$ & $-20.2 \pm 12.8$ & 0.2708 & $-9.3 \pm 9.8$ & $-14.6 \pm 10.7$ & 0.16 \\
\hline $\mathrm{N}-\mathrm{ANS}\left({ }_{\perp} \mathrm{HP}\right)(\mathrm{mm})$ & $55.9 \pm 3.8$ & $57.6 \pm 3.2$ & 0.1135 & $56.0 \pm 3.8$ & $57.3 \pm 3.4$ & 0.29 \\
\hline ANS-Gn $\left({ }_{\perp} \mathrm{HP}\right)(\mathrm{mm})$ & $69.3 \pm 7.1$ & $67.4 \pm 6.1$ & 0.9650 & $69.7 \pm 7.6$ & $68.3 \pm 5.9$ & 0.56 \\
\hline PNS-N $\left({ }_{\perp} \mathrm{HP}\right)(\mathrm{mm})$ & $56.1 \pm 4.0$ & $56.8 \pm 4.4$ & 0.4327 & $56.3 \pm 4.3$ & $55.2 \pm 3.4$ & 0.42 \\
\hline Mand Plane-HP $\left(^{\circ}\right)$ & $29.6 \pm 7.2$ & $33.8 \pm 8.3$ & 0.1140 & $28.4 \pm 6.6$ & $33.2 \pm 8.3$ & 0.09 \\
\hline $\mathrm{U} 1-\mathrm{NF}\left({ }_{\perp} \mathrm{HP}\right)(\mathrm{mm})$ & $30.3 \pm 4.1$ & $30.7 \pm 3.4$ & 0.3627 & $30.3 \pm 4.1$ & $30.6 \pm 3.4$ & 0.81 \\
\hline U6-NF $\left({ }_{\perp} \mathrm{HP}\right)(\mathrm{mm})$ & $24.0 \pm 3.4$ & $24.0 \pm 2.1$ & 0.5024 & $24.2 \pm 3.4$ & $23.9 \pm 2.1$ & 0.72 \\
\hline L6-MP $\left({ }_{\perp} \mathrm{HP}\right)(\mathrm{mm})$ & $31.5 \pm 5.1$ & $30.5 \pm 2.9$ & 0.7505 & $30.7 \pm 4.9$ & $29.7 \pm 2.4$ & 0.44 \\
\hline $\mathrm{L} 1-\mathrm{MP}\left({ }_{\perp} \mathrm{HP}\right)(\mathrm{mm})$ & $40.3 \pm 4.6$ & $39.1 \pm 3.9$ & 0.9374 & $38.9 \pm 5.1$ & $37.1 \pm 3.6$ & 0.25 \\
\hline PNS-ANS (HP) (mm) & $56.6 \pm 5.2$ & $56.8 \pm 4.1$ & 0.7825 & $56.5 \pm 5.0$ & $56.3 \pm 3.9$ & 0.88 \\
\hline $\operatorname{Ar}-\mathrm{Go}(\mathrm{mm})$ & $53.1 \pm 6.8$ & $51.0 \pm 8.6$ & 0.5506 & $52.0 \pm 6.2$ & $50.2 \pm 5.9$ & 0.41 \\
\hline Go-Pg (mm) & $69.2 \pm 6.6$ & $67.3 \pm 7.4$ & 0.6214 & $74.7 \pm 6.0$ & $73.1 \pm 6.8$ & 0.51 \\
\hline B-Pg (MP) (mm) & $6.9 \pm 2.4$ & $7.3 \pm 2.70$ & 0.4443 & $6.5 \pm 2.7$ & $5.8 \pm 2.2$ & 0.37 \\
\hline $\operatorname{Ar}-\mathrm{Go}-\mathrm{Gn}\left({ }^{\circ}\right)$ & $122.3 \pm 3.5$ & $124.5 \pm 6.4$ & 0.2429 & $123.8 \pm 5.1$ & $125.0 \pm 6.2$ & 0.57 \\
\hline $\mathrm{OP}-\mathrm{HP}\left({ }^{\circ}\right)$ & $9.2 \pm 4.9$ & $12.0 \pm 6.8$ & 0.2295 & $8.5 \pm 4.8$ & $13.7 \pm 5.2$ & 0.11 \\
\hline $\mathrm{U} 1-\mathrm{NF}\left(^{\circ}\right)$ & $114.9 \pm 7.1$ & $114.1 \pm 9.2$ & 0.2888 & $115.2 \pm 7.5$ & $113.3 \pm 9.0$ & 0.54 \\
\hline L1/Go-Me $\left(^{\circ}\right)$ & $99.5 \pm 7.3$ & $96.6 \pm 8.5$ & 0.1524 & $98.9 \pm 8.1$ & $97.5 \pm 7.4$ & 0.63 \\
\hline $\mathrm{A}-\mathrm{B}(/ / \mathrm{OP})(\mathrm{mm})$ & $-6.8 \pm 5.1$ & $-8.0 \pm 3.4$ & 0.3371 & $-2.0 \pm 3.2$ & $0.4 \pm 3.3$ & 0.06 \\
\hline
\end{tabular}

Cephalometric pre-operative mean pre-operative start forms for advancement only (BSSO-) and advancement with constriction (BSSO+). * $P<0.05$. 
the non-constriction group with no difference between groups. The mandibular plane exhibited a statistically significant decrease $\left(1.2^{\circ}\right.$, $P<0.05)$ in the advancement only group and no difference in the mandibular advancement alone group. Post-surgically (T2), there was no difference in mandibular plane between groups. Post-surgically, soft tissue changes were observed with decreases in the angle of facial convexity (N-A-Pg), upper lip protrusion (UL-SnPg'), lower lip protrusion (LL-SnPg') and interlabial gap reduction in both groups. Mandibular projection (G-Pg') increased in both groups. Dentally, the lower incisor intruded in both groups ( $2.0 \mathrm{~mm}$ vs $1.3 \mathrm{~mm}$ ) however; there was no difference between groups. Transversely, the mandibular advancement with constriction patients exhibited an average of $2.1 \mathrm{~mm}$ of constriction at the first molar and $0.8 \mathrm{~mm}$ at the canine.

\section{2 | 3-Dimensional analysis results}

The mandibular advancement with constriction patients exhibited wider intermolar ( $38.5 \mathrm{~mm}$ vs $35 \mathrm{~mm}$ ) and intercanine dimensions ( $27.8 \mathrm{~mm}$ vs $26.1 \mathrm{~mm}$ ) at the start of treatment (Table 2). At the conclusion, mandibular advancement with constriction patients exhibited similar intermolar distances as the mandibular advancement without constriction patients ( $36.3 \mathrm{~mm}$ vs $33.8 \mathrm{~mm}$ ) and intercanine distances ( $26.9 \mathrm{~mm}$ vs $24.9 \mathrm{~mm}$ ).

Airway volume $\left(8.68 \mathrm{~mm}^{3}, 4.29 \mathrm{~mm}^{3}\right)$ and cross-sectional airway measures increased at multiple sites within both the mandibular advancement with constriction (6 sites) and the mandibular advancement alone groups (11 sites). Between groups, a single statistically significant difference was observed for the minimum crosssectional area in the region between C2 and C3 (Table 3).

\section{4 | DISCUSSION}

To compare two different techniques, patients with similar presurgical cephalometric measures were selected. In addition, the amount of advancement was similar. An expected difference between treatment groups was the intermolar and intercanine widths. At the start, mandibular advancement with constriction patients exhibited wider intermolar (38.3 $\mathrm{mm}$ vs $33.7 \mathrm{~mm}$ ) and intercanine dimensions ( $27.8 \mathrm{~mm}$ vs $25.9 \mathrm{~mm}$ ). At the conclusion of treatment, mandibular advancement with constriction patients exhibited similar intermolar distances as the mandibular advancement without constriction patients $(36.2 \mathrm{~mm}$ vs $33.6 \mathrm{~mm}$ ) and intercanine distances ( $26.5 \mathrm{~mm}$ vs $25.9 \mathrm{~mm}$ ).

Both groups experienced significant skeletal mandibular advancement. The amount of advancement was nearly identical with only $0.3 \mathrm{~mm}$ more advancement $(P>0.05)$ in the constriction group yielding a homogenous group of patients for direct comparison of the impact on two different surgical protocols.

Difficulties in measuring changes in airway space due to differences in head position have been reported previously. ${ }^{23,24}$ Craniocervical angle change was used in the present study to assure consistent head position during their CBCT scan. By controlling head

TAB LE 2 Airway mean measurements pre-operatively (T1) and post-operatively (T2)

\begin{tabular}{|c|c|c|c|c|c|c|}
\hline \multirow[b]{2}{*}{ Measure } & \multicolumn{3}{|c|}{ BSSO- } & \multicolumn{3}{|c|}{ BSSO+ } \\
\hline & $\mathrm{T} 1$ & T2 & $P$ & $\mathrm{~T} 1$ & $\mathrm{~T} 2$ & $P$ \\
\hline Volume PP-C3 $\left(\mathrm{cm}^{3}\right)$ & $13.59 \pm 4.70$ & $22.28 \pm 8.03$ & * & $21.3 \pm 10.9$ & $25.6 \pm 8.6$ & * \\
\hline Volume PP-C2 $\left(\mathrm{cm}^{3}\right)$ & $11.15 \pm 4.04$ & $18.12 \pm 7.03$ & $*$ & $17.5 \pm 7.3$ & $21.6 \pm 7.2$ & * \\
\hline $\mathrm{mCSA}$ PP-C3 $\left(\mathrm{mm}^{2}\right)$ & $123.44 \pm 62.14$ & $242.96 \pm 108.34$ & * & $198.2 \pm 125$ & $217.8 \pm 140.2$ & NS \\
\hline $\mathrm{mCSA} C 1-\mathrm{C} 2\left(\mathrm{~mm}^{2}\right)$ & $136.61 \pm 67.04$ & $281.26 \pm 126.09$ & * & $237.4 \pm 149.3$ & $351.3 \pm 166.5$ & * \\
\hline $\mathrm{mCSA} C 2-\mathrm{C} 3\left(\mathrm{~mm}^{2}\right)$ & $140.06 \pm 65.76$ & $277.24 \pm 124.66$ & * & $296.1 \pm 214.7$ & $294.5 \pm 198.5$ & NS \\
\hline mCSA S-I C3 (mm) & $22.6 \pm 12.40$ & $13.86 \pm 11.81$ & * & $15.1 \pm 16.2$ & $7.5 \pm 14.5$ & NS \\
\hline mCSA S-I C2 (mm) & $12.52 \pm 12.53$ & $14.42 \pm 14.51$ & $*$ & $8.4 \pm 10.9$ & $5.9 \pm 13.5$ & NS \\
\hline Craniocervical angle $\left(^{\circ}\right)$ & $108.53 \pm 7.50$ & $107.69 \pm 6.96$ & NS & $119.6 \pm 8.1$ & $118.1 \pm 7.2$ & NS \\
\hline $\begin{array}{l}\text { R-L gonial angle distance } \\
(\mathrm{mm})\end{array}$ & $85.51 \pm 7.49$ & $90.27 \pm 7.09$ & $*$ & $84.9 \pm 6.64$ & $87.1 \pm 7.92$ & * \\
\hline $\begin{array}{l}\text { R-L lower molar distance } \\
(\mathrm{mm})\end{array}$ & $33.7 \pm 2.35$ & $33.56 \pm 2.23$ & NS & $38.3 \pm 3.25$ & $36.2 \pm 3.6$ & * \\
\hline $\begin{array}{l}\text { R-L lower canine distance } \\
(\mathrm{mm})\end{array}$ & $25.9 \pm 2.37$ & $25.94 \pm 2.54$ & NS & $27.8 \pm 2.46$ & $26.5 \pm 2.64$ & NS \\
\hline
\end{tabular}

Pre-operative and post-operative airway volume, minimum cross-sectional areas (mCSA), and transverse changes for the mandibular advancement alone (BSSO-) and mandibular advancement with constriction (BSSO+) groups. Statistical significance (T1-T2) within groups noted as ${ }^{*} P<0.05$, ${ }^{* *} P<0.01$ and ${ }^{* * *} P<0.001$. 
TABLE 3 Comparison of 3D airway changes between mandibular advancement without (-) and mandibular advancement with $(+)$ constriction

\begin{tabular}{|llll|}
\hline Measure & BSSO (-) & BSSO (+) & $P$ \\
\hline Advancement $(\mathrm{mm})$ & 5.5 & 5.8 & $\mathrm{NS}$ \\
\hline Volume PP-C3 $\left(\mathrm{cm}^{3}\right)$ & 8.68 & 4.29 & $\mathrm{NS}$ \\
\hline Volume PP-C2 $\left(\mathrm{cm}^{3}\right)$ & 6.79 & 4.11 & $\mathrm{NS}$ \\
\hline mCSA PP-C3 $\left(\mathrm{mm}^{2}\right)$ & 119.52 & 19.65 & $0.0047^{* *}$ \\
\hline mCSA PP-C2 $\left(\mathrm{mm}^{2}\right)$ & 150.65 & 153.88 & $\mathrm{NS}$ \\
\hline mCSA PP-C1 $\left(\mathrm{mm}^{2}\right)$ & 126.70 & 98.81 & $\mathrm{NS}$ \\
\hline mCSA C1-C2 $\left(\mathrm{mm}^{2}\right)$ & 144.65 & 113.97 & $\mathrm{NS}$ \\
\hline mCSA C2-C3 $\left(\mathrm{mm}^{2}\right)$ & 137.17 & -1.6 & $0.0229^{*}$ \\
\hline mCSA S-I C3 $\left(\mathrm{mm}^{2}\right)$ & -8.73 & -7.62 & $\mathrm{NS}$ \\
\hline mCSA S-I C2 $\left(\mathrm{mm}^{2}\right)$ & 1.894 & -2.46 & $\mathrm{NS}$ \\
\hline CSA @ AI C1 $\left(\mathrm{mm}^{2}\right)$ & 127.03 & 80.4 & $\mathrm{NS}$ \\
\hline CSA @ AI C2 $\left(\mathrm{mm}^{2}\right)$ & 174.04 & 133.9 & $\mathrm{NS}$ \\
\hline CSA @ Al C3 $\left(\mathrm{mm}^{2}\right)$ & 107.12 & -39.25 & $\mathrm{NS}$ \\
\hline Craniocervical angle $\left(^{\circ}\right)$ & -0.83 & -1.31 & $\mathrm{NS}$ \\
\hline R-L gonial angle distance $(\mathrm{mm})$ & 4.76 & 2.21 & $\mathrm{NS}$ \\
\hline R-L lower molar distance $(\mathrm{mm})$ & -0.13 & -2.11 & $\mathrm{NS}$ \\
\hline R-L lower canine distance $(\mathrm{mm})$ & 0.04 & -1.33 & $\mathrm{NS}$ \\
\hline
\end{tabular}

Change in pre-operative and post-operative airway volume, minimum cross-sectional areas (mCSA), and transverse changes between the mandibular advancement alone (BSSO-) and mandibular advancement with constriction (BSSO+) groups. Statistical significance (Welches unpaired $t$ test between groups) noted as ${ }^{*} P<0.05,{ }^{* *} P<0.01$ and ${ }^{* * *} P<0.001$. Welches unpaired $t$ test was performed.

position via the craniocervical angle $(P>0.05)$, the observed differences can only be the result of surgery.

To date, there is no consensus regarding airway measurement on CBCTs. Many different approaches, different computer programs, different regions of interest and/or different segmentations are reported. Current consensus is that airway should be measured in 3D rather than in 2D to obtain not only the transverse measures, but also airway volumes. Many previous publications recommend creating a region of interest by extending and connecting lines from palatal plane (anterior nasal spine to posterior nasal spine), the posterior pharyngeal wall, and a line tangent to hyoid that is parallel to palatal plane, and finally back superiorly to posterior nasal spine. To account for differences in oral volume, patients are instructed to place the tongue in a consistent position without swallowing. In this investigation, hyoid was not visible in all patients so the inferior boundary was modified to be a line parallel to palatal plane that was tangent to the anterior-inferior border of the third cervical vertebra (C3). ${ }^{21,25,26}$ The airway was further subdivided to assess possible changes in retropalatal (palatal plane to $\mathrm{C} 1$ ), retroglossal (C1-C2) and hypoglossal (C2-C3) regions since constriction might have a variable effect in each region.

As anticipated from previous investigations, the airway volume and cross-sectional areas increased at many levels in both groups. The advancement alone group experienced more sites of enlargement (11 sites) than the advancement with constriction group (6 sites). The amount of volume increase in the mandibular advancement alone group was nearly twice that of the mandibular advancement with constriction group (8.68 vs $4.29 \mathrm{~cm}^{3}$ ). However, post-surgically, both groups demonstrated similar airway volumes (25.6 vs $\left.22.3 \mathrm{~cm}^{3}\right)$.

The change in minimum cross-sectional areas (mCSA) in the retropalatal and retroglossal regions were equivalent. The change in location of the minimum cross-sectional area was also consistent between groups.

Within the hypoglossal region a difference was observed with the constriction group demonstrating a small decrease $\left(1.6 \mathrm{~mm}^{2}\right)$, and the advancement only group showing an increase $\left(137.2 \mathrm{~mm}^{2}\right)$ in the minimum cross-sectional area. As the mandible constricts, laxity can be created within the mylohyoid and associated posterior mandibular muscle groups. This observation was observed again in the cross-sectional area at the anterior-inferior aspect of C3. Among mandibular advancement only patients, an increase of $107 \mathrm{~mm}^{2}$ was observed while among the constriction group, a decrease of $39.2 \mathrm{~mm}^{2}$ was observed.

Unfortunately, gonial angle changes have not been described in the literature extensively since mandibular advancement with constriction is less common. The information that is available comes from posterior-anterior cephalograms that are prone to interpretation errors due to patient positioning and overlapping structures. Angle et $\mathrm{al}^{27}$ reported an intergonial angle width increase of $6.5 \mathrm{~mm}$ and changes in the angulation of the proximal segments of $3.2^{\circ}$ post-operatively. Becktor et al ${ }^{28}$ reported a $5.6 \mathrm{~mm}$ increase in the gonial angle region when evaluating posterior-anterior cephalograms. In the current investigation, the gonial angle distance increased $4.7 \mathrm{~mm}$ in the advancement only group and $2.2 \mathrm{~mm}$ in the advancement with constriction group. The smaller expansion is expected because the proximal segment does not have to rotate as much.

\section{5 | CONCLUSIONS}

The investigation suggests that mandibular advancement with constriction is not only effective in correcting the malocclusion but also does not negatively affect airway volume. Specific findings were as follows:

1. Both Class II mandibular advancement alone and mandibular advancement with constriction patients show statistically significant increases in airway volume following surgery.

2. Mandibular advancement alone patients gained nearly twice as much airway space as mandibular advancement with constriction patients.

3. Mandibular advancement alone patients showed statistically significantly larger increases in minimum axial area of the PAS when measured to between palatal plane and C 3 with the largest difference observed between C2 and C3. 
ORCID

R. Scott Conley iD https://orcid.org/0000-0002-4888-4875

\section{REFERENCES}

1. Frazier-Bowers S, Rincon-Rodriguez R, Zhou J, Alexander K, Lange E. Evidence of linkage in a Hispanic cohort with a Class III dentofacial phenotype. J Dent Res. 2009;88:56-60.

2. Chew MT. Spectrum and management of dentofacial deformities in a multiethnic Asian population. Angle Orthod. 2006;76:806-809.

3. da Fontoura CS, Miller SF, Wehby GL, et al. Candidate gene analyses of skeletal variation in malocclusion. J Dent Res. 2015;94:913-920.

4. Proffit WR, Fields Jr HW, Moray LJ. Prevalence of malocclusion and orthodontic treatment need in the United States: estimates from the NHANES III survey. Int J Adult Orthodon Orthognath Surg. 1998;13:97-106.

5. Bratu DC, Balan RA, Szuhanek CA, et al. Craniofacial morphology in patients with Angle Class II division 2 malocclusion. Rom J Morphol Embryol. 2014;55:909-913.

6. Rothstein T, Yoon-Tarlie C. Dental and facial skeletal characteristics and growth of males and females with class II, division 1 malocclusion between the ages of 10 and 14 (revisited)-part I: characteristics of size, form, and position. Am J Orthod Dentofacial Orthop. 2000;117:320-332.

7. Proffit WR, White Jr RP. Who needs surgical-orthodontic treatment? Int J Adult Orthodon Orthognath Surg. 1990;5:81-89.

8. Flores-Mir C, Korayem M, Heo G, et al. Craniofacial morphological characteristics in children with obstructive sleep apnea syndrome: a systematic review and meta-analysis. J Am Dent Assoc. 2013;144:269-277.

9. Peppard PE, Young $\mathrm{T}$, Barnet $\mathrm{JH}$, et al. Increased prevalence of sleep-disordered breathing in adults. Am J Epidemiol. 2013;177:1006-1014.

10. van der Linden C, van der Linden WJ, Reyneke JP. Skeletal stability following mandibular advancement with and without advancement genioplasty. Int J Oral Maxillofac Surg. 2015;44:621-626.

11. Brandtner C, Hachleitner J, Rippel C, Krenkel C, Gaggl A. Longterm skeletal and dental stability after orthognathic surgery of the maxillo-mandibular complex in Class II patients with transverse discrepancies. J Craniomaxillofac Surg. 2015;43:1516-1521.

12. Bloomquist D. Mandibular narrowing: advantage in transverse problems. J Oral Maxillofac Surg. 2004;62:365-368.

13. Kurt G, Altug AT, Turker G, et al. Effects of surgical and nonsurgical rapid maxillary expansion on palatal structures. J Craniofac Surg. 2017;28:775-780.

14. Bailey LJ, White RP, Proffit WR, Turvey TA. Segmental lefort i osteotomy for management of transverse maxillary deficiency. J Oral Maxillofac Surg. 1997;55:728-731.
15. Joondeph DR, Bloomquist D. Mandibular midline osteotomy for constriction. Am J Orthod Dentofacial Orthop. 2004;126:268-270.

16. Yu LF, Anthony Pogrel M, Ajayi M. Pharyngeal airway changes associated with mandibular advancement. J Oral Maxillofac Surg. 1994;52:40-43.

17. Turnbull NR, Battagel JM. The effects of orthognathic surgery on pharyngeal airway dimensions and quality of sleep. $J$ Orthod. 2000;27:235-247.

18. Sriram SG, Andrade NN. Cephalometric evaluation of the pharyngeal airway space after orthognathic surgery and distraction osteogenesis of the jaw bones. Indian J Plast Surg. 2014;47:346-353.

19. Bear SE, Priest JH. Sleep apnea syndrome: correction with surgical advancement of the mandible. J Oral Surg. 1980;38:543-549.

20. Hong JS, Park YH, Kim YJ, Hong SM, Oh KM. Three-dimensional changes in pharyngeal airway in skeletal class III patients undergoing orthognathic surgery. J Oral Maxillofac Surg. 2011;69:e401-e408.

21. Schneider D, Kammerer PW, Schon G, Bschorer R. A threedimensional comparison of the pharyngeal airway after mandibular distraction osteogenesis and bilateral sagittal split osteotomy. $J$ Craniomaxillofac Surg. 2015;43:1632-1637.

22. Hsieh YJ, Chen YC, Chen YA, Liao YF, Chen YR. Effect of bimaxillary rotational setback surgery on upper airway structure in skeletal class III deformities. Plast Reconstr Surg. 2015;135:361e-369e.

23. Ozbek MM, Miyamoto K, Lowe AA, Fleetham JA. Natural head posture, upper airway morphology and obstructive sleep apnoea severity in adults. Eur J Orthod. 1998;20:133-143.

24. Solow B, Tallgren A. Head posture and craniofacial morphology. Am J Phys Anthropol. 1976;44:417-435.

25. Claudino LV, Mattos CT, Ruellas AC, Sant'Anna EF. Pharyngeal airway characterization in adolescents related to facial skeletal pattern: a preliminary study. Am J Orthod Dentofacial Orthop. 2013;143:799-809.

26. Sutherland K, Lee RW, Phillips CL, et al. Effect of weight loss on upper airway size and facial fat in men with obstructive sleep apnoea. Thorax. 2011;66:797-803.

27. Angle AD, Rebellato J, Sheats RD. Transverse displacement of the proximal segment after bilateral sagittal split osteotomy advancement and its effect on relapse. J Oral Maxillofac Surg. 2007;65:50-59.

28. Becktor JP, Rebellato J, Becktor KB, et al. Transverse displacement of the proximal segment after bilateral sagittal osteotomy. J Oral Maxillofac Surg. 2002;60:395-403.

How to cite this article: Furche S, Edwards SP, Aronovich S, et al. 3D Airway changes using cone beam computed tomography in patients following mandibular advancement surgery with and without constriction. Orthod Craniofac Res. 2019;22(Suppl. 1):36-42. https://doi.org/10.1111/ocr.12292 